\title{
Differentiation Between Actinobacillus actinomycetemcomitans and Haemophilus aphrophilus by High-Resolution, Two-Dimensional Protein Electrophoresis
}

\author{
EGIL JELLUM, ${ }^{1 *}$ VIGDIS TINGELSTAD, ${ }^{1}$ AND INGAR OLSEN ${ }^{2}$ \\ Institute of Clinical Biochemistry, Rikshospitalet, Oslo $1,{ }^{1}$ and Department of Microbiology, Dental Faculty, University of \\ Oslo, Oslo, ${ }^{2}$ Norway
}

\begin{abstract}
The cellular proteins of eight strains of Actinobacillus actinomycetemcomitans and seven strains of Haemophilus aphrophilus were analyzed by two-dimensional electrophoresis and silver staining. The electrophoretic patterns of $A$. actinomycetemcomitans and $H$. aphrophilus were so different that distinction between these closely related bacteria could easily be made. There were also minor quantitative and qualitative differences in the protein patterns of strains within both species, enabling, particularly, $A$. actinomycetemcomitans strains FDC 2097 and FDC Y4 and H. aphrophilus strains ATCC 19415, FDC 626, and FDC 621 to be singled out.
\end{abstract}

Actinobacillus actinomycetemcomitans and Haemophilus aphrophilus are small, nonmotile, nonsporulating, capnophilic, gram-negative rod-shaped bacteria. Compared with $H$. aphrophilus, A. actinomycetemcomitans is believed to be more widely disseminated in human bodies, residing as a member of the normal flora of upper respiratory tracts and oral cavities, or as a part of the predominant flora in bacterial endocarditis $(16,30,32)$. Both organisms are indigenous to dental plaque, but they are usually present in small numbers (15). Several recent investigations of clinical $(21,27,28)$, serological (33), toxicological (9), and animal model character (11) have implicated $A$. actinomycetemcomitans as a major pathogen in periodontal destruction, particularly in juveniles. The periopathogenic potential of haemophili is traditionally considered small (25), and $H$. aphrophilus has not yet been assigned any clear role in periodontal diseases. If there is a difference in the clinical significance of $A$. actinomycetemcomitans and $H$. aphrophilus, it is imperative to distinguish between these two species. Alternatively, if $H$. aphrophilus has a role in human disease, this cannot be demonstrated adequately unless the organism is properly identified. Unfortunately, representative strains of $A$. actinomycetemcomitans and $H$. aphrophilus are morphologically and biochemically quite similar, and differentiation in laboratories routinely is based only on a few physiological characters (26). The similarity in features may lead to misdiagnosis, and the distinction between these species has been questioned. Gas chromatography of cellular fatty acids has become an important tool for taxonomic differentiation between facultative bacteria $(17,24)$. Examinations of bound whole-cell fatty acids $(3,5,7,12)$ and fatty acids in lipopolysaccharide and lipid A (6) from A. actinomycetemcomitans and $H$. aphrophilus revealed no differences between these species. On the basis of gas chromatography of free cellular fatty acids, A. actinomycetemcomitans strains could be arranged into a major cluster and a minor cluster; the fatty acid content of the major cluster of strains was similar to the fatty acid content of $H$. aphrophilus strains, but the content of the minor cluster differed (4). We have also been able to

\footnotetext{
* Corresponding author.
}

use D-glycero-D-mannoheptose in lipopolysaccharide as a taxonomic marker for differentiating between A. actinomycetemcomitans and $H$. aphrophilus since this aldoheptose was detected exclusively in A. actinomycetemcomitans (I. Brondz and I. Olsen, J. Chromatogr., in press). When the deoxyribonucleic acid relatedness of $A$. actinomycetemcomitans and $H$. aphrophilus strains was examined, it was found that $A$. actinomycetemcomitans strains formed a distinct group different from the group of $H$. aphrophilus strains (8). Another method for taxonomic differentiation between bacteria is examination of cytoplasmic protein patterns by onedimensional polyacrylamide gel electrophoresis. When this technique was used, A. actinomycetemcomitans and $H$. aphrophilus appeared to have distinct protein profiles, but the analyses did not differentiate between strains within the species (7). The one-dimensional technique is also inadequate in cases of pleiotrophic effectors, development transitions, or mutations (22). In the present study a high-resolution, two-dimensional electrophoretic technique $(1,2,13,22)$ was used to determine the cellular protein patterns of $A$. actinomycetemcomitans and $H$. aphrophilus. Our data demonstrate that by means of the two-dimensional electrophoretic method one can readily differentiate between $A$. actinomycetemcomitans and $H$. aphrophilus and even delimit strains within both species.

The strains of $A$. actinomycetemcomitans and $H$. aphrophilus analyzed are listed in Table 1. Strains ATCC 33384, ATCC 33389, ATCC 19415, and ATCC 13252 were obtained directly from the American Type Culture Collection, strain HK435 was obtained from M. Kilian, Aarhus, Denmark, and the other strains were obtained through the Forsyth Dental Center. The organisms were cultivated in brain heart infusion (Difco Laboratories, Detroit, Mich.) broth in air containing $10 \% \mathrm{CO}_{2}$ for 5 days at $37^{\circ} \mathrm{C}$, harvested by centrifugation, washed three times in deionized, distilled water, and lyophilized over di-phosphorus pentoxide (E. Merck AG, Darmstadt, Germany). All cultivations were made in duplicate on different days.

Acrylamide, bisacrylamide $(N, N$-methylenebisacrylamide), urea, and sodium dodecyl sulfate were products of Bio-Rad Laboratories, Richmond, Calif., and Serva Feinbio- 

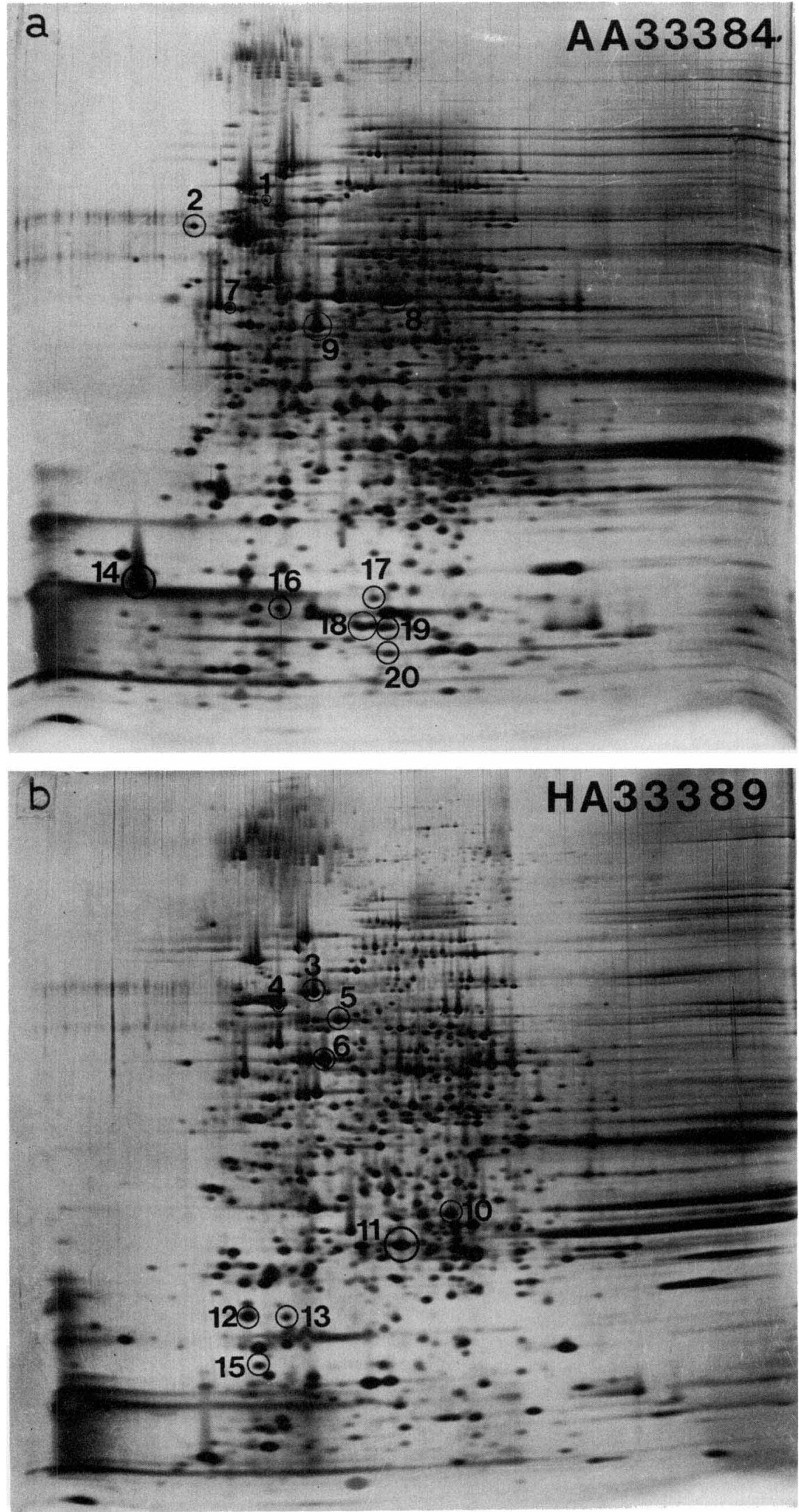

FIG. 1. Two-dimensional electrophoretic protein patterns of $A$. actinomycetemcomitans type strain NCTC 9710 (a) and $H$. aphrophilus type strain NCTC 5906 (b). Silver staining was used to visualize spots. The experimental details are described in the text. The numbered spots represent some of the differences (i.e., proteins which are present in one type strain but not in the other). 

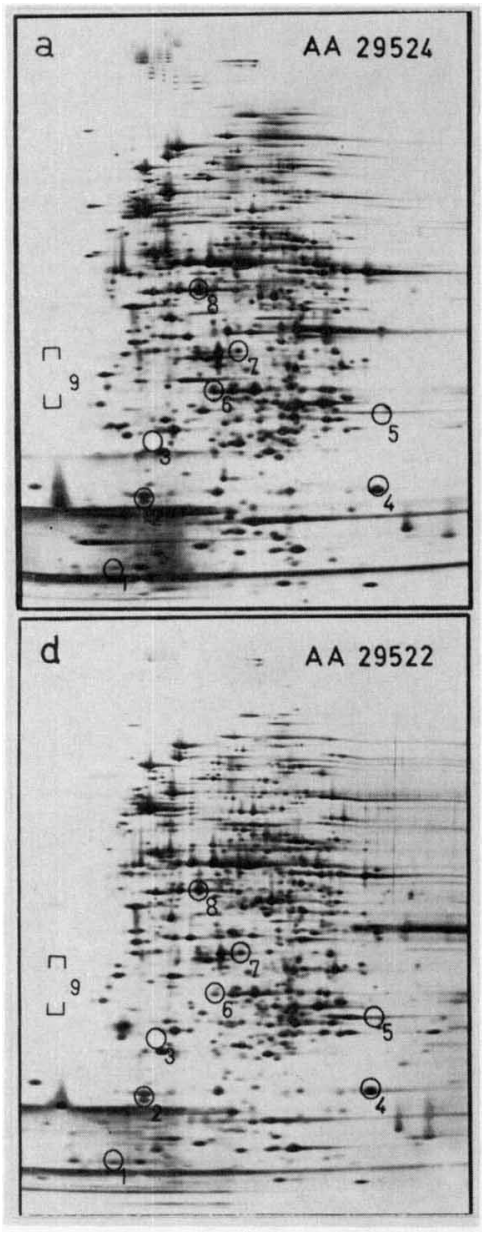
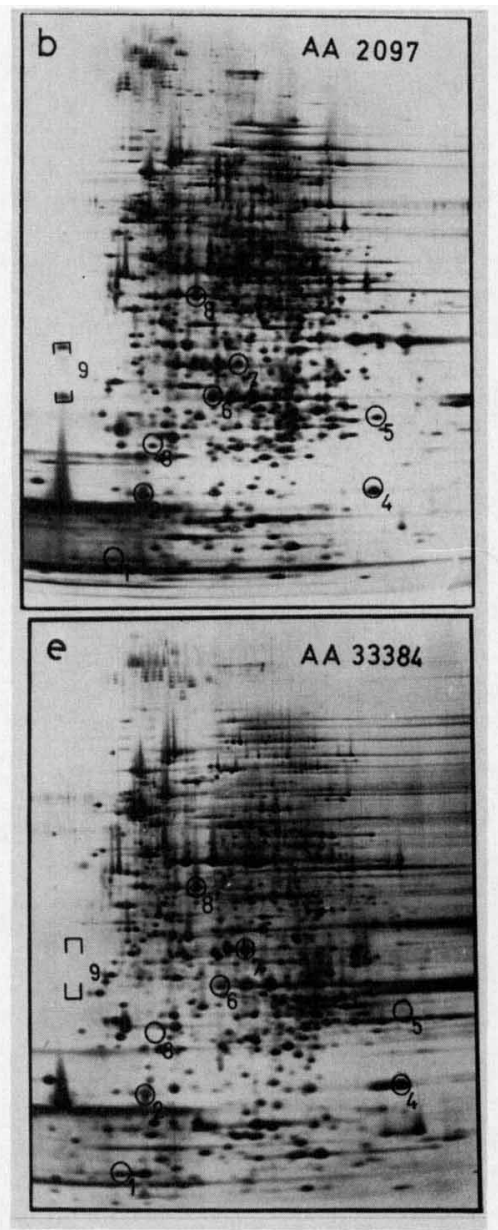

INT. J. SyST. BACTERIOL.
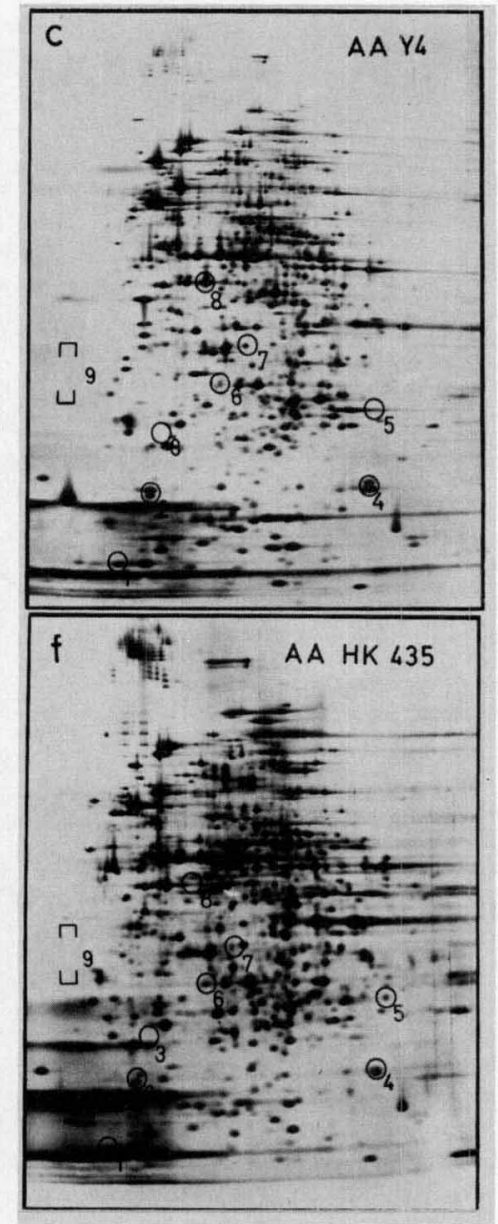

FIG. 2. Two-dimensional electrophoretic protein patterns of $A$. actinomycetemcomitans type strain NCTC 9710 (e) and the following five other A. actinomycetemcomitans strains: ATCC 29524 (a), FDC 2097 (b), FDC Y4 (c), ATCC 29522 (d), and HK435 (f). Differentiating spots are numbered 1 through 9.

chemica, Heidelberg, Germany. The ampholytes used for isoelectric focusing were Ampholines (LKB, Stockholm, Sweden). Nonidet P-40 was a product of Sigma Chemical Co., St. Louis, Mo. All other chemicals used for electrophoresis were commercially available analytical grade products.

The equipment for high-resolution, two-dimensional electrophoresis was obtained from Electro-Nucleonics, Oak Ridge, Tenn. This apparatus is based on the ISO-DALT system described by Anderson and Anderson $(1,2)$. The ISO apparatus allows isoelectric focusing of 20 samples at a time, and two DALT tanks were used, each holding 10 polyacrylamide gels. The power supplies used were an LKB model 3371 power supply for isoelectric focusing and a model HP6448B power supply (Hewlett-Packard, San Diego, Calif.) for the second dimension. A model 2160 refrigerating bath (Forma Scientific, Marietta, Ohio) was used to keep the temperature near $10^{\circ} \mathrm{C}$ during the latter electrophoresis. The samples were centrifuged in a microfuge (Microfuge B; Beckman Instruments, Inc., Palo Alto, Calif.) before electrophoresis. After staining, the gels were photographed by using a Polaroid MP-4 Land camera and negative film of the Plus-X Pan professional type (Eastman Kodak Co., Rochester, N.Y.). Photographic prints (Agfa-Gevaert Rapitone P12) were made in an automatic developer (Rapidoprint DD 1437; Agfa-Gaevert).

Lyophilized bacterial cells $(5 \mathrm{mg})$ were dissolved in $500 \mu \mathrm{l}$ of a buffer containing $9 \mathrm{M}$ urea, $50 \mathrm{ml}$ of 2-mercaptoethanol per liter, $20 \mathrm{ml}$ of Ampholines per liter, and $40 \mathrm{ml}$ of the nonionic detergent Nonidet $\mathrm{P}-40$ per liter. The samples were frozen and thawed three or four times and were centrifuged for approximately $1 \mathrm{~min}$ in the microcentrifuge to sediment

TABLE 1. Bacteria investigated

\begin{tabular}{lll}
\hline \multicolumn{1}{c}{ Strain } & Original source $^{a}$ & \multicolumn{1}{c}{ Site of origin } \\
\hline $\begin{array}{lll}\text { A. actinomycetemcomitans } \\
33384\left(9710^{\mathrm{T}}\right)\end{array}$ & & \\
29524 & ATCC (NCTC) & Lung abscess \\
29522 & ATCC & Chest aspirate \\
HK 435 & ATCC & Mandibular abscess \\
2097 & Kilian & Pus \\
511 & FDC & Periodontitis \\
N27 & FDC & Periodontitis \\
Y4 & FDC & Periodontosis \\
& FDC & Periodontosis \\
H. aphrophilus & & \\
$33389\left(5906^{\mathrm{T}}\right)$ & ATCC (NCTC) & Endocarditis \\
$19415(5886)$ & ATCC (NCTC) & Endocarditis \\
13252 & ATCC & Unknown \\
655 & FDC & Periodontitis \\
654 & FDC & Periodontitis \\
626 & FDC & Periodontosis \\
621 & FDC & Periodontosis \\
\hline
\end{tabular}

${ }^{a}$ ATCC, American Type Culture Collection, Rockville, Md.; NCTC, National Collection of Type Cultures, London, England; FDC, Forsyth Dental Center, Boston, Mass. 

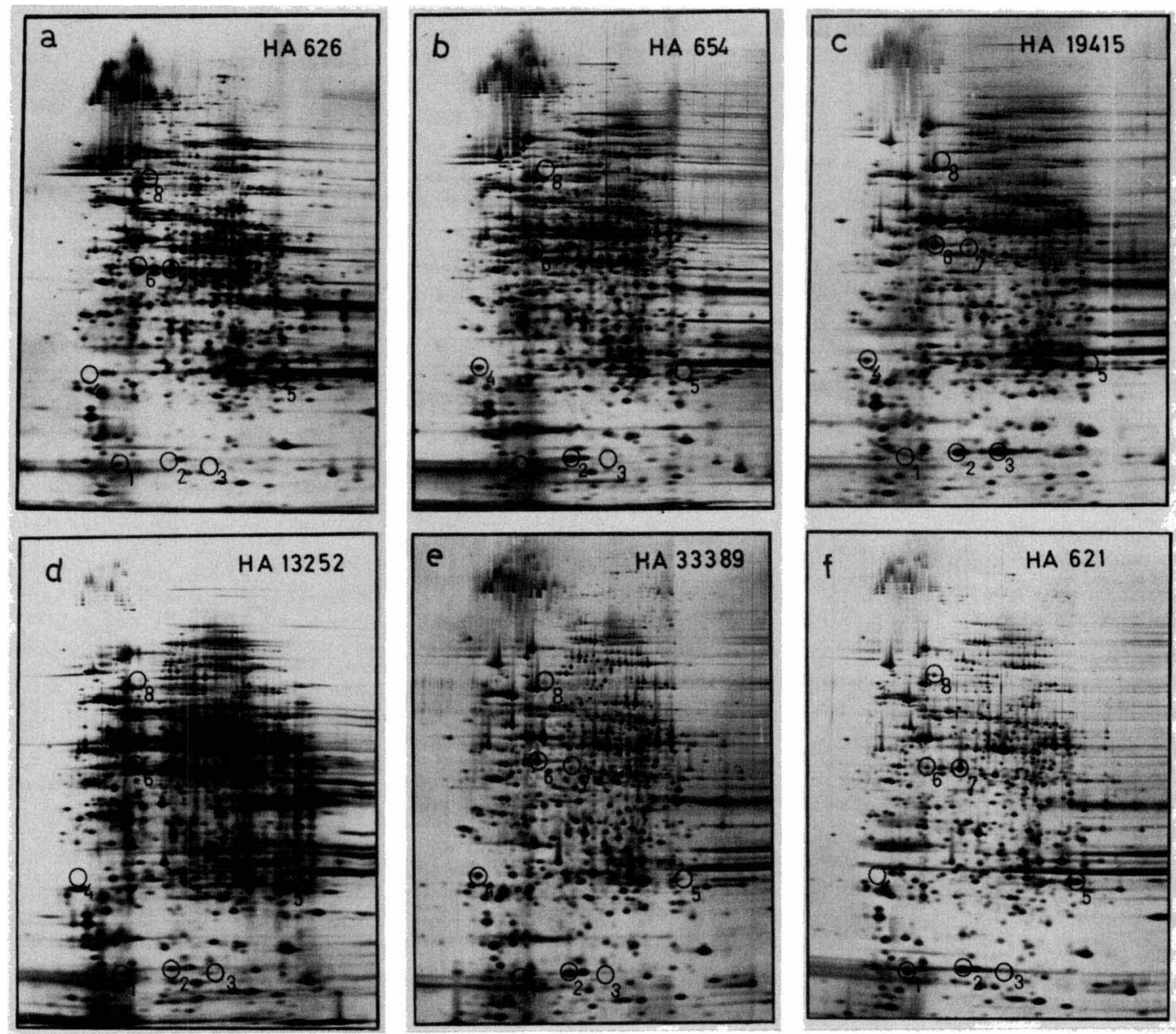

FIG. 3. Two-dimensional electrophoretic protein patterns of $H$. aphrophilus type strain NCTC 5906 (e) and the following five other $H$. aphrophilus strains: FDC 626 (a), FDC 654 (b), ATCC 19415 (c), ATCC 13252 (d), and FDC 621 (f). Differentiating spots are numbered 1 through 8 . (The numbering of spots is not the same as in Fig. 2.)

the insoluble material. Samples $(10 \mu \mathrm{l})$ of the supernatants were analyzed by high-resolution, two-dimensional electrophoresis.

After electrophoresis in the second dimension, the gels were fixed and stained by using the silver staining method described by Tracy et al. (31).

The protein patterns of batches grown at different times were quite reproducible. Figure 1 shows the two-dimensional electrophoretic protein patterns of the type strains of $A$. actinomycetemcomitans and $H$. aphrophilus. Some of the several differences which may be used to differentiate between these bacteria are indicated by circles, which indicate "isolate-specific" proteins (20). Figure 2 shows the protein patterns of five strains of $A$. actinomycetemcomitans in addition to the type strain (Fig. 2e). All of the protein maps show a considerable degree of similarity, but there are also characteristic differences that are both qualitative and quantitative in nature. The most important spots to consider in this context are indicated and are designated spots 1 through 9. Spots 1,6 , and 7 are present in all A. actinomycetemcomitans strains, but vary in quantity. Circle 2 is composed of two spots on top of each other, and the relative proportions of these spots vary. In strain ATCC 29524 (Fig. 2a) the top spot dominates, whereas in strain FDC 2097 (Fig. 2b) the bottom spot is clearly present in larger quantities. Spots 3 and 9 are only present in strain FDC 2097 (Fig. 2b) and can be used to differentiate this strain from the other strains of $A$. actinomycetemcomitans. Circle 4 encloses a double spot in strain FDC Y4 (Fig. 2c), and a single spot occurs in all of the other strains of $A$. actinomycetemcomitans. Spot 5 is found only in strains FDC 2097 (Fig. 2b) and HK435 (Fig. 2f). Accordingly, it is easy to single out strains FDC 2097 and FDC Y 4 by means of the qualitative differences in their twodimensional protein patterns, whereas it is more difficult to differentiate between the other strains of A. actinomycetemcomitans, where the differences in the protein patterns are of a more quantitative type.

Figure 3 shows the two-dimensional protein patterns of five strains of $H$. aphrophilus, together with the pattern of the type strain of this species (Fig. 3e). Important differentiating spots are indicated and are designated spots 1 through 8 (these are not the same spots that occur in Fig. 2). Spot 1 is found only in three strains (strains FDC 626, FDC 621, and ATCC 13252); spot 2 is virtually absent in strain FDC 626 (Fig. 3a) and may be used to single out this strain. Spot 3 is one of the major spots in strain ATCC 19415 (Fig. 3c) and is absent in all of the other strains of $H$. aphrophilus. Therefore, spot 3 is characteristic of strain ATCC 19415. Spot 4, like spot 1 , occurs only in three of the $H$. aphrophilus strains, but not always in the same strains as spot 1 . Spots 5 and 8 are the major spots in strains FDC 626 (Fig. 3a) and FDC 621 (Fig. 3f) and are nearly absent in the other strains. Spots 6 and 7 show major quantitative differences. Accordingly, it is possible to single out strains ATCC 19415, FDC 
626, and FDC 621 from the information given in Fig. 3, whereas differentiation of the other strains based on differences in the protein maps is more uncertain.

Our data on the cellular proteins of $A$. actinomycetemcomitans and $H$. aphrophilus demonstrate that these species, although related, are clearly distinct. This supports the establishment of $A$. actinomycetemcomitans as a distinct species in Bergey's Manual of Systematic Bacteriology, 9th ed. (23). A. actinomycetemcomitans should probably not be included in the genus Haemophilus (14) unless the description of this genus is changed. It should be realized that differences on the species level do not exclude relatedness at the genus or family level. Consistent with this is the proposal for creating a new family that includes Haemophilus, Actinobacillus, and Pasteurella $(18,29)$.

The high resolution of the technique which we used made it possible to differentiate not only between the two species, but also among strains within each species. In particular, in A. actinomycetemcomitans strains FDC 2097 and FDC Y4 could be singled out, and in $H$. aphrophilus strains ATCC 19415, FDC 626, and FDC 621 were distinguishable. This was in contrast to the results achieved with one-dimensional polyacrylamide gel electrophoresis (7). Although several of the strains which we examined in this work were included in the one-dimensional electrophoresis study, differentiation between strains within $A$. actinomycetemcomitans and $H$. aphrophilus was not possible. Whether delimitation of specific strains, as achieved in this study, warrants creation of subspecies within $A$. actinomycetemcomitans and $H$. aphrophilus will have to await further examinations. Efforts have been made to divide $A$. actinomycetemcomitans strains into serogroups, biotypes, and groups differing in leukotoxic activity. As far as we know, similar subdivision has not been attempted for $H$. aphrophilus. A. actinomycetemcomitans strains arranged into such groups differed from subgroups of A. actinomycetemcomitans established by cluster and multidimensional scaling analyses of phenotypic features (29), indicating that the taxonomic significance of sero-, biotype and leukotoxic grouping has yet to be demonstrated. This was partly supported by our findings. Both strain FDC 2097 and strain FDC Y4 have been placed into the same serogroup, together with strains such as strains ATCC 29524, ATCC 29522, and FDC N27 (19). Strain FDC 511 constitutes a separate serogroup (19). Both of these serogroups contain exclusively leukotoxic strains. Interestingly, the leukotoxin is a soluble, heat-labile, protease-sensitive protein (9). Furthermore, the type strain of $A$. actinomycetemcomitans represents a distinct serogroup (33). It should also be mentioned that strains ATCC 29524, ATCC 29522, and FDC Y4 have been grouped in the same biotype (27).

In this study strain FDC Y4 differed from all of the other strains of $A$. actinomycetemcomitans, especially through its double spot in area 4 (Fig. 2c). It should be realized that this strain has been assigned a particularly high periodontopathic potential in humans and animals $(11,33)$. Previously, we have found that strain FDC Y4 differs from most other strains of $A$. actinomycetemcomitans by its content of the free cellular acid iso- $C_{15: 0}$ acid (4). There are also differences in biochemical reactions between strain FDC Y4 and reference strains of $A$. actinomycetemcomitans, such as strains ATCC 29524, ATCC 29523, and ATCC 29522 (9). Furthermore, it has been demonstrated through fixation and staining with ruthenium red that the outer membrane of strain FDC Y4 cells stains more intensely than the outer membranes of other gram-negative bacteria similarly prepared (10). Efforts are presently being made to characterize the proteins in strain FDC Y4 that are most different from the proteins of the other strains of A. actinomycetemcomitans in an attempt to provide a better understanding of the biochemical basis for the higher virulence of this species.

It appears from this study that two-dimensional electrophoresis has a high potential in chemotaxonomy, particularly in cases involving closely related bacteria that are hard to distinguish with conventional laboratory tests. The exceedingly detailed and specific fingerprint system provided by this technique may lead to more accurate identification and more refined classification of bacteria.

\section{LITERATURE CITED}

1. Anderson, N. G., and N. L. Anderson. 1978. Analytical techniques for cell fractions. XXI. Two-dimensional analysis of serum and tissue proteins: multiple isoelectric focusing. Anal. Biochem. 85:331-340.

2. Anderson, N. L., and N. G. Anderson. 1978. Analytical techniques and cell fractions. XXII. Two-dimensional analysis of serum and tissue proteins: multiple gradient-slab gel electrophoresis. Anal. Biochem. 85:341-354.

3. Braunthal, S. D., S. C. Holt, A. C. R. Tanner, and S. S. Socransky. 1980. Cellular fatty acid composition of Actinobacillus actinomycetemcomitans and Haemophilus aphrophilus. J. Clin. Microbiol. 11:625-630.

4. Brondz, I., and I. Olsen. 1983. Differentiation of Actinobacillus actinomycetemcomitans from Haemophilus aphrophilus by gas chromatography of hexane extracts from whole cells. J. Chromatogr. 278:13-23.

5. Brondz, I., and I. Olsen. 1984. Determination of bound cellular fatty acids in Actinobacillus actinomycetemcomitans and Haemophilus aphrophilus by gas chromatography and gas chromatography-mass spectrometry. J. Chromatogr. 308:282-288.

6. Brondz, I., and I. Olsen. 1984. Determination of acids in whole lipopolysaccharide and in free lipid A from Actinobacillus actinomycetemcomitans and Haemophilus aphrophilus. J. Chromatogr. 308:19-29.

7. Calhoon, D. A., W. R. Mayberry, and J. Slots. 1981. Cellular fatty acid and soluble protein composition of Actinobacillus actinomycetemcomitans and related organisms. J. Clin. Microbiol. 14:376-382.

8. Coykendall, A. L., J. Setterfield, and J. Slots. 1983. Deoxyribonucleic acid relatedness among Actinobacillus actinomycetemcomitans, Haemophilus aphrophilus, and other Actinobacillus species. Int. J. Syst. Bacteriol, 33:422-424.

9. Hammond, B. F., and R. H. Stevens. 1982. Capnocytophaga and Actinobacillus actinomycetemcomitans: occurrence and pathogenic potential in juvenile periodontitis, p. 46-61. In R. J. Genco and S. E. Mergenhagen (ed.), Host-parasite interactions in periodontal diseases. American Society for Microbiology, Washington, D.C

10. Holt, S. C., A. C. R. Tanner, and S. S. Socransky. 1980. Morphology and ultrastructure of oral strains of Actinobacillus actinomycetemcomitans and Haemophilus aphrophilus. Infect. Immun. 30:588-600.

11. Irving, J. T., M. G. Newman, S. S. Socransky, and J. D. Heeley. 1975. Histological changes in experimental periodontal disease in rats monoinfected with a gram-negative organism. Arch. Oral Biol. 20:219-220.

12. Jantzen, E., B. P. Berdal, and T. Omland. 1980. Cellular fatty acid composition of Haemophilus species, Pasteurella multocida, Actinobacillus actinomycetemcomitans and Haemophilus vaginalis (Corynebacterium vaginale). Acta Pathol. Microbiol. Scand. Sect. B 88:89-93.

13. Jellum, E., and A. K. Thorsrud. 1982. Clinical applications of two-dimensional electrophoresis. Clin. Chem. 28:876-883.

14. Kilian, M. 1976. A taxonomic study of the genus Haemophilus, with the proposal of a new species. J. Gen. Microbiol. 93:9-62.

15. Kilian, M., and C. R. Schiøtt. 1975. Haemophili and related bacteria in the human oral cavity. Arch. Oral Biol 20:791-796.

16. King, E. O., and H. W. Tatum. 1962. Actinobacillus actinomy- 
cetemcomitans and Hemophilus aphrophilus. J. Infect. Dis. 111:85-94.

17. Lechevalier, M. 1977. Lipids in bacterial taxonomy-a taxonomist's view. Crit. Rev. Microbiol. 5:109-210.

18. Mannheim, W., S. Pohl, and R. Hollander. 1980. On the taxonomy of Actinobacillus, Haemophilus, and Pasteurella: DNA base composition, respiratory quinones, and biochemical reactions of representative collection cultures. Zentralbl. Bakteriol. Parasitenkd. Infektionskr. Hyg. Abt. 1 Orig. Reihe A 246:512-540.

19. McArthur, W. P., C.-C. Tsai, P. Baehni, B. J. Shenker, and N. S. Taichman. 1982. Noncytolytic effects of Actinobacillus actinomycetemcomitans on leukocyte function, p. 179-192. In R. J. Genco and S. E. Mergenhagen (ed.), Host-parasite interactions in periodontal diseases. American Society for Microbiology, Washington, D.C.

20. Mouches, C., J. C. Vignault, J. G. Tully, R. F. Whitcomb, and J. M. Bové. 1979. Characterization of spiroplasmas by one- and two-dimensional protein analysis on polyacrylamide slab gels. Curr. Microbiol. 2:69-74.

21. Newman, M. G., S. S. Socransky, E. D. Savitt, D. A. Propas, and A. Crawford. 1976. Studies on the microbiology of periodontosis. J. Periodontol. 47:373-379.

22. O'Farrell, P. H. 1975. High resolution two-dimensional electrophoresis of proteins. J. Biol. Chem. 250:4007-4021.

23. Phillips, J. E. 1984. Genus Actinobacillus Brumpt 1910, 849, p. 570-576. In N. R. Krieg (ed.), Bergey's manual of systematic bacteriology, 9th ed. The Williams \& Wilkins Co., Baltimore.

24. Shaw, N. 1974. Lipid composition as a guide to the classification of bacteria. Adv. Appl. Microbiol. 17:63-108.

25. Sims, W. 1972. Lack of association between haemophili and human periodontal disease. Arch. Oral Biol. 17:1029-1033.

26. Slots, J. 1982. Salient biochemical characters of Actinobacillus actinomycetemcomitans. Arch. Microbiol. 131:60-67.

27. Slots, J., H. S. Reynolds, and R. J. Genco. 1980. Actinobacillus actinomycetemcomitans in human periodontal disease: crosssectional microbiological investigation. Infect. Immun. 29:1013-1020.

28. Tanner, A. C. R., C. Haffer, G. T. Bratthall, R. A. Visconti, and S. S. Socransky. 1979. A study of the bacteria associated with advancing periodontitis in man. J. Clin. Periodontol. 6:278-307.

29. Tanner, A. C. R., R. A. Visconti, S. S. Socransky, and S. C. Holt. 1982. Classification and identification of Actinobacillus actinomycetemcomitans and Haemophilus aphrophilus by cluster analysis and deoxyribonucleic acid hybridizations. J. Periodontal Res. 17:585-596.

30. Thjøtta, T., and S. Sydnes. 1951. Actinobacillus actinomycetemcomitans as the sole infecting agent in a human being. Acta Pathol. Microbiol. Scand. 28:27-35.

31. Tracy, R. P., R. M. Currie and D. S. Young. 1982. Two-dimensional gel electrophoresis of serum specimens from a normal population. Clin. Chem. 28:890-899.

32. Vandepitte, J., H. De Geest, and P. Jousten. 1977. Subacute bacterial endocarditis due to Actinobacillus actinomycetemcomitans. J. Clin. Pathol. 30:842-846.

33. Zambon, J. J., J. Slots, and R. J. Genco. 1983. Serology of oral Actinobacillus actinomycetemcomitans and serotype distribution in human periodontal disease. Infect. Immun. 41:19-27. 